\title{
El discurso irónico en Endlich Kokain de Joachim Lottmann
}

Cristina Paneque de la Torre (cristina.paneque@uv.es)

Universitat de València

\section{Resumen}

La Popliteratur se caracteriza por describir situaciones y problemáticas, a priori, frívolas y cotidianas, propias de una generación joven, pero que sirven para desarrollar relatos que ahondan en una temática más profunda e individual como la soledad, la alienación del individuo o la necesidad de éxito social y económico para la valoración personal y global. Los textos de la Popliteratur están plagados de referencias a marcas, música, símbolos de estatus económico y social pero, sobre todo, de la ironía como recurso para presentar estos temas y los problemas que suscitan en el individuo. Joachim Lottmann es uno de los máximos exponentes de este estilo literario, plagado de ironía y situaciones complejas por su extravagancia. En el presente trabajo trataremos el análisis de su discurso irónico en la novela Endlich Kokain a partir de las tres formas de distinción presentadas por Christoph Rauen: Entpflichtung, Inversion y Relativierung.

Palabras clave: Popliteratur, Joachim Lottmann, ironía, Camp, New Journalism.

\section{Ironic Discourse in Joachim Lottmann's Endlich Kokain}

\section{Abstract}

Popliteratur is characterized by the description of situations and difficulties which can beforehand seem trivial and quotidian. They can be understood as something typical of a young generation, but these descriptions help to develop tales that delve into topics 
such as loneliness, distortion or the need of social and economic success to achieve personal and general worth. The texts that belong to Popliteratur are riddled with references to trademarks, music and symbols of economic and social status, but they are specially riddled with ironic sentences that are used as resources to present these topics and the problems they can cause to the individual. Joachim Lottmann is one of the clearest examples of this literary style, full of irony and complex situations due to its oddness. The present article analyzes ironic discourse in the novel Endlich Kokain from the perspective of the three factors of distinction presented by Christoph Rauen: Entpflichtung, Inversion and Relativierung.

Keywords: Popliteratur, Joachim Lottmann, irony, Camp, New Journalism.

\section{Introducción}

La Popliteratur gozó de una gran popularidad a finales de los años 90 y principios del siglo XXI. Caracterizada desde sus inicios por reflejar con intensidad las experiencias del día a día de la Spaßgesellschaft,${ }^{1}$ ha sido acusada de superficial y frívola, etiquetada como Jugendliteratur e incluso presentada como literatura no seria: "In den 1990er Jahren wurden mit der Bezeichnung Pop in erster Linie Begriffe assoziiert wie jugendlich, massentauglich, anti-intelektuell” (Mehrfort 46). La definición que podemos encontrar en Metzler Literatur Lexikon también acompaña a las apreciaciones recogidas por Mehrfort:

Pop-Literatur [anglo-amerik. aus popular $=$ allgem. verständl.], an den Begriff Pop-Art angelehnte Bez. für die Literatur der sog. Pop-Kultur. Zu unterscheiden ist 1. die populäre Unterhaltungsliteratur (auch KommerzPop), wie ihn etwa die Zeitschriften Life, Playboy, twen, 
Bravo anbieten und 2. eine Literatur, die mit provokanter Exzentrik, Monomanie, Obszönität, Unsinnigkeit und Primivität gegen eine derart. Unterhaltungsliteratur ebenso gerichtet ist wie gegen eine Elite-Kunst, gegen etablierte ästhet. Normen. (Schweikle y Schweikle 359)

Pero esta supuesta literatura de la superficialidad, obra de autores en su mayoría veinteañeros y noveles, no solo habla de temas menores como las preocupaciones diarias de un grupo de jóvenes ajenos a los avatares de la política nacional e internacional, aparentemente interesados únicamente por la diversión, la acumulación de bienes de consumo que los posicionen socialmente y por presentarse como los grandes triunfadores, sino que nos presenta temas tan trascendentales como las crisis existenciales que sufren sus protagonistas y la alienación a la que se someten para poder encajar en una sociedad retratada como materialista y consumidora compulsiva. La preocupación por el devenir del sujeto es otro de los temas centrales en estas obras, que se ayudarán de un discurso con el que sus autores se sienten representados, plagado de referencias a los mass media, a la música pop, a la diversión banal y al mundo de las marcas, en el que la ironía desempeña un papel importante como modo de representación de esta realidad.

Desde Christian Kracht con la publicación en 1995 del personal retrato de Alemania en Faserland, pasando por la figura del joven anhelante de éxito social y económico del protagonista de Soloalbum de Benjamin von Stuckrad-Barre en 1998, hasta la percepción que se hace de las relaciones amorosas con Relax de Alexa Hennig von Lange, también en 1998, el lector encuentra multitud de reflexiones acerca de la vida y sus normas, las exigencias sociales y la alienación del individuo para intentar formar parte del todo social. El deseo frente a la obligación, la necesidad de obtener el beneplácito de los demás y de sentirse integrados y valorados sin perder su esencia individual son el leitmotiv de este movimiento literario.

Los autores pertenecientes a este estilo elegirán un lenguaje dinámico y de fácil comprensión para expresarse, encontrando en la ironía el recurso perfecto para representar sus tribulaciones, pues esta 
conlleva una dualidad en su significado -la diferencia entre lo que se dice y lo que realmente se quiere decir-que es compartida por estos literatos, quienes al hablar de sus experiencias en un mundo de aparente disfrute y diversión también nos relatan la soledad y las presiones a las que se enfrenta el individuo y sus ansias de ser aceptado por la sociedad.

Junto a estos autores destaca, no solo por su obra sino también por su capacidad para ponerse en escena, Joachim Lottmann, de quien analizaremos Endlich Kokain, publicada en 2014 y uno de los máximos exponentes del estilo literario del autor, ya que reúne todas las características estilísticas que ha ido desarrollando a lo largo de su dilatada carrera literaria, desde sus comienzos previos al auge de la literatura pop, y que continua vigente en la actualidad. El desarrollo de este análisis partirá de los conceptos de Entpflichtung, Relativierung e Inversion desarrollados por Christoph Rauen (Rauen 4 y siguientes).

\section{Joachim Lottmann: El eiron del Pop}

Lottmann (Hamburgo, 1959) es uno de los máximos exponentes de la literatura pop alemana del siglo XXI. Galardonado en 2010 con el Wolfgang-Koeppen-Literaturpreis, es un autor y periodista prolífico, narrador de la actualidad y de los problemas que en ella confluyen haciendo gala de un talante controvertido y un estilo inmune a toda corrección política.

Estudió Artes Escénicas y Filología Alemana en su ciudad natal y trabaja como periodista, colaborando con medios como TAZ, Frankfurter Allgemeine Sonntagszeitung, Süddeutsche Zeitung, Die Welt, Spiegel, y escritor. Debutó en 1987 con la novela Mai, Juni, Juli, que le sirvió para (auto)proclamarse precursor del movimiento pop que inundaría las estanterías de las librerías alemanas en los años 90. Tras ella se publicarán en la editorial Kiepenheuer \& Witsch sus posteriores obras: Deutsche Einheit (1999), Die Jugend von heute (2004), Der Geldkomplex (2009), Endlich Kokain (2014) o Alles Lüge (2017), entre otras.

Es necesario tener en cuenta que todas las obras de Joachim Lottmann se caracterizan por mostrar un estrecho compromiso con la 
actualidad que las rodea. Este compromiso es representado en sus novelas mediante situaciones sensibles a la polémica y ligadas a la sociedad alemana. Si en Deutsche Einheit encontramos un relato que analiza la recepción de la reunificación en la sociedad alemana, Der Geldkomplex habla sobre la crisis económica en la que Europa se ve sumida en la presente década y Alles Lüge realiza un recorrido por la crisis de los refugiados, el Brexit y la situación económica de Grecia. Son obras actuales en las que Lottmann denuncia situaciones que pueden verse normalizadas pero que no deberían serlo, ayudándose para ello de su experiencia en el ámbito periodístico.

Para definirle como periodista podemos circunscribir sus textos dentro del contexto del New Journalism ${ }^{2}$ (Kreknin 280) y como escritor utilizaremos las palabras de Innokentij Kreknin:

Joachim Lottmann ist das paradoxe Konstrukt eines Subjekts, das sich jeder Festlegung entzieht. Seine literarischen und seine journalistischen Texte ergeben ein Amalgam, in welchem ein Universum entsteht, das einem oberflächlichen Blick zufolge zahlreiche Referenzen auf unsere Alltagswirklichkeit offeriert - nur um sich bei einer genaueren Prüfung als heterogene Sammlung von Elementen zu erweisen, deren Konfiguration vollkommen unklar verbleibt. (Kreknin 280)

Otros críticos como Volkers Weidermann o Rainald Goetz lo describen de la siguiente forma:

Sohn des FDP-Mitbegründers Joachim Lottmann, genialer Weltmitschreiber, Lügner, Prahlhans, Fälscher, Erfinder der deutschen Popliteratur, Großvater der deutschen Popliteratur, Anwalt aller Enkel, Allesfotograf und Allesschreiber, Schaumschläger, Geschichtendieb, Über-Ich-AG, Weiterschreiber, merkwürdiger Mensch. (Weidermann 227)

Er hat ja immer behauptet, die Reportage wäre der letzte wahre Ort für Literatur, für Fiktion. Und er schrieb dann Porträts und Reportagen, wo das Echte und Erfundene sich auf wirklich irritierende Weise 
mischten. Eigentlich ja vielleicht toll. Aber durch die inszenierte Undurchsichtigkeit und Verschlagenheit von Joachim Lottmann selbst bekam das einen fiesen Stich ins Diabolische. Ich hatte Angst vor ihm. (Goetz 500)

La calificación de Lottmann como un personaje complejo y ambiguo responde a la necesidad de catalogar a un autor difícilmente catalogable, pues no solo su forma de escribir nos acerca al estilo periodístico del New Journalism, sino que las características inherentes a su personalidad hacen que produzca textos explícitos y reveladores de realidades incómodas pero, a su vez, envueltos en un halo de ambigüedad debido al carácter borderline y mitómano ${ }^{3}$ del que el autor hace gala. El síndrome borderline ha sido ampliamente estudiado desde finales del siglo XIX; para Sendera y Sendera los principales rasgos que caracterizan a las personas con este síndrome son los siguientes:

Borderline-Betroffener zu sein bedeutet auch, eine enorme Sensitivität, eine besondere Emotionalität, sowie ein großes Einführungsvermögen zu haben und Menschen gegenüber absolut loyal zu sein, die es geschafft haben, ihr Vertrauen zu gewinnen. Die besondere Kreativität und Sprachgewandtheit gehören bei ihnen genauso dazu wie ein facettenreiches Persönlichkeitsbild, sie sind häufig sehr charmant, sehr phantasievoll, hilfsbereit, flexibel und oftmals überdurchschnittlich intelligent. Sie erkennen den Kern einer Sache sofort und erfassen Situationen intuitiv, sie geben nicht auf und haben einen ausgeprägten Gerechtigkeitssinn. (Sendera y Sendera 22)

Lottmann no duda en afirmar que su relación con la veracidad es dudosa, proporcionando a preguntas directas, como la realizada por el conductor del programa Willkommen Österreich, respuestas ambiguas y evasivas.

STERMANN: Wir haben vorher [...] erfahren, dass Du dafür bekannt bist, zu lügen. Beziehungsweise, die Menschen empfinden das als Lüge, was Du machst 
[...]. Die Frage ist jetzt: Wie können wir dann ein Gespräch führen; also, brauchen wir irgendwie so eine Art anderen Zugang zu Antworten von Dir oder ist das was Du sagst...würdest Du das gar nicht als Lüge bezeichnen dann?

LOTTMANN: Nein, niemals, also: Für mich ist es die Wahrheit. Das macht halt dies Borderline-Syndrom aus.

STERMANN: Aber Du hast; leidest unter dem Borderline-Syndrom...

LOTTMANN: [unterbricht ihn]: Ich leide darunter nicht. Ich empfinde es auch gar nicht so. Ich würde es auch niemals wahrnehmen. Es sind halt die Anderen, die mich so bezeichnen. (Willkommen Österreich, $17 / 01 / 2008)$

Para poder analizar la condición de su obra debemos tener en cuenta que en esta no solo confluyen las características del New Journalism, aderezadas por el propio carácter mitómano y borderline del que adolece el autor, sino que hemos de sumar a este conjunto de particularidades estilísticas la sensibilidad $\operatorname{Camp}^{4}$ que presenta Lottmann al conformar el estilo narrativo sobre el que basa sus obras. Esta idiosincrasia ha supuesto afirmaciones tales como "Lottmann verlottmannt die Welt" (Kreknin 2014: 331) referidas tanto a su obra literaria como al conjunto de textos que conforman su producción periodística.

Pese a la dificultad de clasificar al autor de Endlich Kokain en términos convencionales, su narrativa puede ser declarada como campy, en tanto en cuanto lo Camp significa el amor por la exageración y el artificio, siendo la presencia de elementos extremados y ficticios innegable, tanto por la caracterización de los personajes como por los hechos representados en la obra de Lottmann. En Notes on Camp, Susan Sontag postula lo camp como "a vision of the world in terms of style -but a particular kind of style. It is the love of the exaggerated, the "off," of things-being-what-they-are-not" (Sontag 3).

Este carácter de escritor borderline y campy posibilita en sus relatos una doble intención: por una parte, Lottmann relata la realidad tal y 
como él la percibe, siendo su versión una visión amplificada de la misma y estando esta completamente supeditada a la forma en que Lottmann recibe y considera el mundo; por otra parte, el hecho de que los personajes que acompañan a sus protagonistas estén inspirados en personalidades de cualquier ámbito -literario, artístico o deportivoy que estas sean reconocibles o, incluso, supongan la aparición de personas reales en los textos, implica la pérdida de ficción que en algún momento pudiera entrar en consideración en la recepción del texto. Por lo tanto, podemos considerar que Lottmann crea relatos desde una realidad subjetiva, extrapolada a su propio universo mitómano y borderline, ayudándose de estos protagonistas complejos e inusuales para representar una situación harto inverosímil, guiando al lector hacia el desenmascaramiento de una verdad incómoda, aunque real y que, como ocurrirá en Endlich Kokain, se verá rodeada del glamour más cegador.

Asimismo, sus protagonistas suelen ser periodistas o escritores que evolucionan hacia la mayor de las incorrecciones, llegando a desarrollar un alter ego en la figura de Jolo, en la mayoría de sus novelas. El protagonista emprende una o varias relaciones sentimentales con mujeres jóvenes que, con frecuencia, no duran más que pocas páginas, con suerte una novela completa, y pueden cambiar a lo largo de la narración continuamente, siendo retratadas de una forma criticable, por sexista y repleta de clichés.

Pero a su vez, si tenemos en cuenta el tono marcadamente irónico que reina en sus textos, podemos confirmar que esta incorrección política sirve para denunciar el sistema social establecido y permite al autor hablar sin tapujos ni tabúes sobre el verdadero tema que ocupa cada una de sus obras, esa verdad escondida bajo la pátina de futilidad de la narración. Lottmann no solo plasma la realidad, sino que resalta aquellos aspectos que busca poner de relieve para su análisis, revisión y reflexión. No es solamente un mentiroso, un fanfarrón o un cuentista, es un denunciante de la realidad del siglo XXI, de las situaciones a las que los individuos se ven abocados o provocan.

Si el eiron ${ }^{5}$ era el personaje dramático de la antigua Grecia que simulaba la ignorancia para realizar un discurso de crítica desde la ironía, Lottmann se ha erigido como el eiron del siglo XXI con su denuncia a través de esta. 


\section{Endlich Kokain o el dictado de las apariencias}

Endlich Kokain, publicada en 2014, es descrita por la propia editorial como la representación de una época extasiada y supone una perfecta manifestación de los diferentes métodos con los que la ironía puede aparecer en una obra literaria.

Lottmann nos presenta en esta novela a un protagonista, Stephan Braum, a priori una persona aburrida, común y tranquila si no fuera por un rasgo físico que le condiciona sobremanera: su sobrepeso. Declarado pensionista mucho antes de lo que debería, este divorciado cincuentón de familia acomodada recibe una mala noticia relacionada con el exceso de kilos y la falta de movimiento que lleva acarreando desde hace años: su esperanza de vida es de solo tres años. Pero de todo esto no se hace conocedor al lector/a gracias a una introducción o a una descripción detallada del personaje frente al espejo o a través del monólogo interior; esta información nos llega mediante la conversación que mantiene en las tres primeras páginas de la novela con quien le suministrará cocaína por primera vez.

Lottmann no deja tiempo al lector para el acomodo a lo largo de la novela por la frenética concatenación de los hechos presentados. Este frenesí en la acción dificultará la reflexión durante el tiempo de lectura de la novela por la variedad de hechos relatados y de personajes que intervienen. Las conclusiones extraídas por el lector/a en un determinado momento sobre los personajes se verán invalidadas por la rapidez con que estos cambian de parecer y de actitud, desarrollando la ironía desde diferentes puntos.

La ironía aparece representada mediante la paradoja, que invadirá la obra en su totalidad, provocando la sorpresa, el estupor y la incomodidad en un lector/a que se encuentra ante numerosos personajes, siendo algunos de ellos personajes reales como Boris Becker o Diedrich Diederichsen y otros inspirados en personas reales -véase a Martin Kippenberger rebautizado en la novela como Joseph Hölzl o al galerista Harry Lybke caracterizado como Harry Schmeling- así como aquellos salidos de la imaginación del autor, pero que bien podrían representar a cualquier segmento de la población. 
Estos personajes, con el protagonista Braum a la cabeza, llevarán a cabo todo tipo de acciones reprochables pero justificables a sus ojos. Para ilustrarlo comenzaremos nuestro análisis por el protagonista quien, para cuidar su salud y bajar de peso, decide recurrir al consumo de cocaína y documentarlo en lo que él bautiza como diario científico o W.T. (Wissenschaftliches Tagebuch). La cocaína permite a Braum recorrer un camino de éxito desde Viena hasta Berlín, con la mentira como cimiento de su estrenada situación de reconocimiento social.

La combinación de estos dos hechos -el intento de mejorar la salud a través del consumo de cocaína y el reconocimiento social que provocan los efectos de esta- crean una situación absolutamente inverosímil que abre la puerta a los temas que realmente se quieren tratar: el dictado de las apariencias y la hipocresía apreciables en la sociedad cuando el éxito social y económico acompañan a una persona, siendo este el objetivo de Endlich Kokain: denunciar la insignificancia del camino hasta el éxito en una sociedad siempre permisiva con quien goza de fama y notoriedad. Braum se convierte, mediante el engaño y sobre todo a través de lo que algunos denominan postureo, ${ }^{6}$ en un exitoso marchante de arte gracias a su inmersión en el mundo de la cocaína y al consumo de drogas que aparece retratado en el ámbito de los artistas.

El amplio abanico de personajes presentados en la novela y las actitudes y acciones que desarrollan son muestra de los diferentes modos de expresar la ironía en esta obra, pues cuando hablamos de ironía, hablamos de un término ambiguo y por ello de difícil comprensión. Se han producido innumerables intentos de definir la ironía desde Sócrates hasta los más recientes estudios en crítica literaria sobre este tema y, sin embargo, no existe una definición unitaria para ella, aunque sí podemos encontrar elementos comunes en todas las versiones expuestas.

Al considerarla, "Sócrates elevó la ironía a sumo artefacto didáctico, el que consiste en simular que se ignora lo que se sabe" (Matamoro 241), mientras que Friedrich Schlegel afirmó que "en la ironía todo debe ser broma y todo debe ser serio, todo debe resultar cándidamente sincero y profundamente simulado a la vez" (Benéitez Andrés 40), y John T. Harwood afirma en un estudio posterior que 
"toda ironía supone un acto de disimulo, fingimiento, enmascaramiento, mentira, desciframiento, de traducción" (Harwood 33). Estas definiciones comparten un elemento: la consideración de la simulación como pieza necesaria para poder producir enunciados irónicos, independientemente del medio en que se presenten.

Además, hemos de tener en cuenta que la Popliteratur centra sus narraciones en personajes ambiguos, controvertidos para mostrar temas perturbadores, especialmente por la manera de presentarlos y las acciones que llevan a cabo sus protagonistas. Por ello, sabedores del efecto contrario que puede tener su mensaje, los Popliteraten utilizan la ironía para distanciarse de las posibles consecuencias de sus palabras, ya que esta debe ser además entendida como "un método de transgredir las reglas lingüístico-sociales, una forma de decir y no decir, una forma de liberar el discurso de sus ataduras públicas" (Santaemilia Ruiz 2001: 216), lo que permite al autor la posibilidad de revocar sus afirmaciones sin sufrir consecuencias. Pero la ironía puede aparecer de formas muy diferentes, ahí reside la dificultad en identificarla y a la vez su valor como forma de expresión para los Popliteraten. Rauen ha reflejado el uso que se hace de la ironía en la obra de Lottmann clasificándola en tres grupos (Rauen 4 y siguientes).

\subsection{Entpflichtung o cómo ser franco sin herir sensibilidades}

El concepto de Entpflichtung fue desarrollado por Eibl, quien consideraba que:

Die entpflichtete Rede ermöglicht es, über Dinge zu reden, über die man -aus den verschiedensten, trivialen wie erhabenen Gründen- eigentlich nicht reden kann oder darf oder soll, über die man aber troztdem reden will oder soll oder muss. Oder in aller Kürze: Die entpflichtete Rede ermöglicht Sprechen über Unaussprechliches, von der Trivialität unaussprechlicher Körperteile und Kleidungsstücke bis zu den unaussprechlichen Geheimnissen der Mystiker. (Eibl 346) 
La ironía sirve a los Popliteraten para referirse a aquello que es cuestionable de ser expresado en público por razones de corrección, proporcionando a las/los autoras/es un cómodo medio de expresión de aquello que no es quizá lo más recomendable expresar, pero sobre lo que entendemos que existe una necesidad de hacer patente, ya sea personal o socialmente. En el caso de los Popliteraten, deberemos recurrir a la definición que hicieron Degler y Paulokat de estos: "Popliteraten inszenieren sich oftmals als Dandys. Sie versuchen, die Vertreter des 'politisch Korrekten' in die Defensive zu treiben, indem sie sich auf keine Meinung endgültig festlegen lassen” (Degler y Paulokat 107).

Considerándolos de esta manera, entendemos que el uso de la ironía por parte de los Popliteraten responde a la necesidad de expresarse sin temor a ser castigados por ello, para lo que hacen valer la ambivalencia de la ironía, el equívoco. Esto ha sido desde siempre una característica unida a la figura del Dandy, definido por Barbey d'Aurevilly como "ein Provokateur, aber ein Provokateur mit Takt" (Barbey d'Aurevilly 27), del que destaca entre otras su capacidad para mantener conversaciones y enunciar los discursos con los comentarios más ácidos y punzantes, en los que es capaz de la mayor de las críticas pero que, a la vez, su impostada figura y maneras hacen que salga indemne de cualquier reacción de su interlocutor. "Sein Witz ist niemals grob, sondern getragen von feinster Ironie" (Erbe 20), y es esta ironía la que, como enuncian Degler y Paulokat, le permite encontrar una salida cuando las consecuencias a sus comentarios pudieran no ser las deseadas o fuera de su control:

Die Ironie ermöglicht es der popmodernen Literatur, sich aus der ästhetischen Sackgasse des Schweigens zu befreien - dem Schweigen der Moderne, die angesichts einer moralischen Weltkomplexität das eigene Sprechen kaum mehr verantworten zu können glaubte. Die Unentschiedenheit, ob geäußerte Sätze tatsächlich so gemeint sind, wie sie gesagt/geschrieben wurden, liefert dem Dandy einen letzten Notausgang, wenn der moralische Druck ab einem bestimmten Grad der Provokation dann doch zu groß werden sollte. (Degler y Paulokat 2008: 107) 
La ironía es representada en su forma de entpflichtete Rede en diversas ocasiones a lo largo de la novela, destacando aquí dos de ellas. La primera ocurre al comienzo de la obra, cuando la acción se desarrolla en Viena y Lottmann describe la permisividad existente en relación al consumo de drogas, pues estas aparecen en todos los estratos sociales y relacionadas con cualquier tipo de personaje, como, por ejemplo, su primer proveedor de cocaína, un periodista bastante exitoso, de buena familia, que asegura haber sido director de la sección de cultura en la $O R F$, descrito de la siguiente manera:

Gleich am ersten Tisch saß mein Mittelsmann, mit Namen Ludwig Fachinger, den ich schon seit Jahren aus der Ferne kenne. Ich lese seine Kolumne im Freitag und kann mir ein Bild von ihm machen. Reicher Sohn, lag dem Vater früher auf der Tasche, vielleicht sogar heute noch. Alter schwer zu sagen, 40? 50? Dem Rotlichtmilieu mitgetan. Politisch eher links als rechts. Später erzählte er mir, daß er Drogen am liebsten von Hurenbrüsten schnieft. Er erzählte auch viel von Kämpfen, die er in dem Staatssender $O R F$ ausgefochten haben will. Da war er einmal, sagte er, Kulturchef gewesen. Ich kann das nicht nachprüfen, will es auch nicht. (Lottmann 22)

El autor nos muestra de forma cruda uno de los aspectos más ignorados en la sociedad actual cuando nos referimos al consumo y tráfico de drogas: este no es inherente exclusivamente a las capas sociales más bajas o problemáticas. Lottmann utiliza la ironía en su versión de entpflichtete Rede para denunciar las ideas preestablecidas que se desarrollan en torno a las personas en función de su origen social, logros profesionales y económicos y poner de manifiesto que el consumo y, sobre todo, el comercio de sustancias estupefacientes son perfectamente atribuibles a personas cultas, formadas y pertenecientes a los círculos sociales más exclusivos.

Este fragmento reúne además las características propias de la narrativa de Lottmann anteriormente mencionadas, incorporando el uso de la ironía asociada al concepto de Entpflichtung. En él se ofrece al lector/a una descripción detallada del personaje en cuestión, 
desempeñando un papel relevante su origen social, la situación familiar y económica y su posicionamiento social y político en un momento de la novela en el que lo verdaderamente importante es la adquisición de cocaína por primera vez por parte del protagonista. Esta narración es realizada mediante una descripción propia del New Journalism y Camp ya que predomina lo no natural, lo artificial e incluso extravagante. De este modo se transforma la seriedad de la situación que presenta en esa frivolidad que forma parte del concepto desarrollado por Sontag y que señalábamos anteriormente.

Esta compleja forma de narrar es mantenida por Lottmann incluso cuando relata las acciones que órganos del estado como la policía suelen acometer en lo relativo a las drogas y su consumo. A lo largo de toda la obra se hace referencia a la permisividad de las autoridades austríacas con el consumo de sustancias estupefacientes y a su normalización social; ejemplo de ello es la siguiente afirmación enunciada por el protagonista:

\section{Liebes W.T.,}

die Verdoppelung der Dosis bei der Mitteleinnahme ist in ihrer Wirkung weiter genauestens zu beobachten. [...] War es daher nicht eine falsche Entscheidung, die Dosis zu verdoppeln? Was war oder ist der Vorteil? Nun, zum einen ist auch die neue Dosis noch gering, also nur ein Bruchteil dessen, was ein normaler Wiener an einem Wochenende verbraucht. Inzwischen weiß ich ja, daß die Songzeile "Ganz Wien / Greift auch zu Kokain" eine realistische Beschreibung des Augenverhaltens breiter Schichten der Bevölkerung darstellt. (Lottmann 2014: 137)

Recordemos que este tipo de ironía manifiesta aquello sobre lo que, a pesar de ser conocido, no existe una voluntad de reconocer y en este fragmento podemos comprobar que el tono frívolo del texto, así como la magnificación de los hechos, parecen restar peso a la crítica y denuncia que se está llevando a cabo.

Debemos recordar que estas afirmaciones vienen dadas por un personaje que pone en riesgo su salud y su vida por el hecho de perder 
peso. Como mencionábamos anteriormente, el texto es protagonizado por un personaje que podría ser una persona cualquiera, pero aquejado de obesidad. Esta condición supone que deba prejubilarse y vivir pendiente de su medicación, así como un carácter inseguro en cuanto a las relaciones sociales. Es una figura que sufre un cambio radical en su personalidad, lo que hace pensar al lector/a que no puede considerar sus aseveraciones literalmente y que muchas de sus afirmaciones y vicisitudes son consecuencia de un espectro mental inseguro, dado a la inestabilidad emocional y por lo tanto no válido para emitir juicios morales o sociales.

Pero esta valoración del personaje debe ser prudente, ya que el lector también es conocedor del aumento del consumo de cocaína que se ha sufrido en la sociedad y consciente de que la cocaína ha estado unida desde finales de los años 80 a la jet set $\mathrm{y}$ al estilo de vida de las estrellas de la música, y que este modus vivendi ha sido uno de los aspectos más normalizados en referencia a la cultura del bienestar y, a su vez, más incorrecto políticamente. La referencia a la canción Ganz Wien ${ }^{7}$ del cantautor austríaco Falco de 1982 al tratar este tema en la novela le infiere un halo de frivolidad, banalizando las consecuencias del consumo de drogas.

La presentación de los elementos a través de un personaje extremadamente peculiar y artificioso dota a la denuncia que subyace en el texto de un carácter aparentemente fútil, pero, junto a la ironía, supone la herramienta que utiliza Lottmann para poder revelar estos hechos de los cuales aunque no se puede, no se debe o no es aconsejable hablar, son considerados por el autor como relevantes y de necesario debate.

\subsection{Inversion: Ironía no apta para descontextualizados}

Para que el resultado de este tipo de ironía sea correcto, esta debe ser señalada, ya que solo así se podrá disociar del engaño o la mentira. Como afirma José Santaemilia:

La ironía supone una infracción de las reglas lingüísticas y exige la cooperación del lector. Para su 
correcta decodificación, la ironía exige al menos del lector las siguientes competencias: la lingüística, la ideológica y la contextual; sin ellas, todo el edificio irónico se desplomaría. (Santaemilia 2001: 216)

Esta apreciación es importante ya que los Popliteraten han sido etiquetados de diversas maneras, no siempre positivas por parte de los críticos, pero en ningún caso han sido catalogados como productores de engaños o mentiras. Siempre han sido entendidos por la crítica como irónicos, gracias en parte al proceso de Inswenierung ${ }^{8}$ que llevaron a cabo en sus años de mayor exposición pública y que ayudó a entenderlos, incluso por parte de aquellos más reacios a comprender su obra globalmente: "Mit Inszenierung ist der Prozess gemeint, an dessen Ende die Performance steht" (Willems 15). Así, la Inszenierung ayudaba a los Popliteraten a contextualizar, también a través de ellos mismos, su obra: su mensaje, su crítica y la representación de los hechos y los personajes que aparecen en sus obras son un reflejo de aquello que les preocupa, con un estilo cercano a la crítica social y a la individualidad del momento que desean mostrar. Paralelamente ayuda al lector/a a una mejor comprensión de su obra, a situar el eje narrativo de manera adecuada y a entender el mensaje en su totalidad, profundizando en él con la posibilidad de dejar al margen los recelos que estas historias pueden despertar en un receptor/a carente de contextualización.

De esta forma, necesitamos compartir una serie de conocimientos previos para poder interpretar el texto en su justa medida, ya sean estos de carácter político, social o cultural, y no entenderlo de forma literal puesto que, en este caso, cualquier crítica u opinión que puedan despertar en el lector/a será siempre producto de una falta de conocimiento del contexto en que se desarrolle la acción. Exactamente igual que no se puede hacer una valoración correcta de aquella conversación que se escucha cuando ya está comenzada, no se pueden valorar los textos de los autores pop sin entenderlos en su totalidad. Esta Inversion también puede ser entendida, según Martínez y Scheffel, como:

[die] 'doppelte Botschaft der Ironie' auf zwei Ebenen: Sender der wörtlichen, unzuverlässigen 
Botschaft ist der Erzähler, Sender der "eigentlich gemeinten" der Autor. Die Zuordnung zum Inversionsmuster ist allerdings fragwürdig, da Erzähler oft nur graduell von der Wahrheit abweichen. (Martínez y Scheffel 101)

Delimitar en el texto dónde acaba el mensaje que emite el narrador y dónde empieza el verdadero mensaje que quiere transmitir el autor es, siempre, una tarea ardua. Aquí la ironía deberá ser perfectamente contextualizada, siendo tarea del receptor/a la de discernir cuál es la finalidad del autor dentro de un texto que, si es entendido de forma literal, será comprendido de modo erróneo. La ironía inunda estas obras con afirmaciones difícilmente analizables sin un conocimiento previo del estilo pop, sensibles a provocar las críticas más complejas y a la vez desacertadas, demostrando que no se ha alcanzado la interpretación del texto en su totalidad y no se ha discernido el mensaje final que nos lanzan los Popliteraten desde sus obras.

En el caso de Endlich Kokain, el recurso de la Inversion es menos abundante que el de la Entpflichtung o de la Relativierung por propias características del autor. Como hemos podido comprobar, Lottmann no es un autor dado a los eufemismos, sino que gusta de un mensaje perceptible y sin tapujos, sin temor a las reacciones de sus lectores o de la crítica. Pese a todo, encontramos algunas situaciones en las que podemos entrever la Inversion.

So orderte ich noch eine zweite Garnitur, die mir zusammen mit dem fleckigen weißen Anzug ins Adlon geschickt wurde. Aus alter Gewohnheit zahlte ich mit Hölzls Platin-Kreditkarte, zum letzten Mal. Ich trug sie aus Versehen immer noch bei mir. Vor Monaten hatte ich sie schützend an mich genommen, damit sie nicht in unbefugte Hände fiel. (Lottmann 240)

Aquí nos habla el protagonista, quien ha estado viviendo durante todo el proceso comatoso del artista Hölzl de sus rentas, en su atelier, vendiendo falsificaciones de sus obras inacabadas con la ayuda de otro artista de menor nivel y el beneplácito de su marchante de arte. La 
consecuencia directa de este comentario final será la socarronería que se desprende de estas líneas.

Braum se ha permitido todo tipo de lujos, naturalmente entre ellos el consumo de droga por parte de todos los personajes que le han acompañado en ese periodo de tiempo. A priori parece un comentario jocoso, con la única intención de despertar la sonrisa en el lector/a, pero si profundizamos un poco más, nos lleva a analizar la falta de escrúpulos aquí representada, así como a reflexionar acerca del tipo de sociedad en que vivimos y construimos, en la que la falta de principios puede ser vista con naturalidad por algunos miembros de ella e incluso llevarlos a ser cómplices activos de estas situaciones.

De nuevo la ironía nos ayuda a presentar circunstancias que necesitarían del debate y a reivindicar su existencia, que pueden prescindir de la corrección política para ser expuestas al ser presentadas por Lottmann a través de la paradoja. No es necesario medir las consecuencias que estas afirmaciones puedan tener en el público, ya que la ironía que presentan es autoridad suficiente para excusarlas.

El lector/a puede comprobar que la divergencia entre el comportamiento del narrador y la concepción que tiene este de sí mismo es muestra del rasgo más característico en Lottmann, el síndrome borderline y la acusada mitomanía que acompaña a su obra. El resultado de la suma de dichas peculiaridades con la Inversion fructifican en un protagonista como Braum, representante de una sociedad en la que la autoevaluación es realizada desde el beneplácito que nos confiere una sociedad individualista, egocéntrica y laxa en los estándares morales, una sociedad en la que la autocrítica está subestimada, siendo esta la denuncia emitida por Lottmann.

\subsection{Relativierung o la búsqueda de la objetividad}

La ironía encuentra en la Relativierung una tercera modalidad, pues como afirma Schlegel, "der Sinn ironischer Äußerungen 'bewege' sich zwischen den Polen Affirmation und Negation" (Rauen 8). Esta versión de la ironía necesita la colaboración de la paradoja, entendida esta como "la presentación de la contradicción que 
representa la vida del narrador o de los personajes: ese choque que se da entre sus aspiraciones y sus hechos, entre sus palabras y sus comportamientos" (Hernández Guerrero 54), ya que en esta contradicción la ironía se transforma en paradoja y la paradoja en ironía, creándose un círculo de difícil ruptura, apoyado además en la comentada Inszenierung de que hacen gala los autores de la narrativa pop alemana. Podríamos decir que el cóctel de ironía y paradoja, tan necesario para poder construir la Relativierung, reina en toda la novela ya que es esta una sucesión de acciones que, como bien indicaba Schlegel, se mueven entre los polos de la afirmación y la negación.

Todo en esta novela se construye en torno a esta paradoja y la acompaña constantemente desde la primera afirmación:

Aber du hast doch sicher schon hier und da gehört, daß es nur ein todsicheres Mittel gegen Übergewicht gibt. Nämlich harte Drogen. Kokain, um genau zu sein. (Lottmann 10)

Siguiendo esta línea de pensamiento, nos encontramos con la descripción de Hölzl:

Da war zum Beispiel der Hölzl, ein stadtbekannter, sogar landesweit bekannter Künstler, Braum kannte ihn gut, ja alle kannten ihn gut. Man wußte auch, daß er exzessiv viel trank, und das liebten alle sogar an ihm. Er war der originellste, lustigste, liebenwerteste Mensch weit und breit, immer zu schrägen Scherzen aufgelegt. [...] Daß er auch kokste, war bekannt und völlig normal. [...] (Lottmann 27)

Resulta llamativo que todos los adjetivos con los que se describe a Hölzl sean positivos y que impliquen el reconocimiento y valoración social, pese a que la adicción a las drogas sea un dato que siempre eclipsa el currículum de cualquier persona. Esta descripción se ve relativizada por la normalización que se hace del abuso en el consumo de alcohol y drogas, amplificado por el entorno en el que se mueve el artista y que se supone normalizado para los pertenecientes a este ámbito. Este personaje podría ser considerado como un dependiente, 
pero su éxito le protege de semejantes valoraciones y es descrito de manera completamente positiva. Así aparece la cuestión de la procedencia del valor de una persona, ¿es este un valor personal o, al contrario, completamente material?

También hemos de considerar representativa en la Relativierung la descripción que se hace de dos de las personas de mayor confianza de Hölzl, su confidente Ursula Töle y su marchante de arte Harry Schmeling, al ser conocedores del entramado de falsificaciones y venta de obras del artista:

Zum Glück waren beide, Ursula Töle und Harry Schmeling, selbst keine Freunde der Polizei. Schmeling war im Gegenteil sehr daran interessiert, seine millionenschwere Ware nicht durch einen Fälschungsskandal zu gefährden. So ähnlich dachte auch Ursula Töle, die ebenfalls ihre persönlichen Aktien im Hölzl-Business hatte. (Lottmann 193)

En estos dos ejemplos aparecen reflejados el capitalismo más deshumanizado y la codicia llevada al extremo. De esta forma, la persona que les ha posibilitado su actual posición social no pasa de ser una mera mercancía, que será utilizada hasta que deje de ser válida o pueda mermar sus intereses. De nuevo aparecen las consideraciones acerca del valor de una persona, si este depende de los bienes materiales que posee y su capacidad para generar riqueza o si deben ser independientes de estos y la intención de denuncia que caracteriza los textos de Lottmann.

La ironía aparece nuevamente como método de denuncia, no solo de este abuso en particular, sino de toda aquella situación moralmente reprochable siendo este un ejemplo magnificado y extremo propio del estilo literario y de concepción vital de Lottmann.

\section{Conclusión}

La ironía es un concepto de compleja definición, que no solo depende de ella misma para existir, sino también de cómo sea 
interpretada, obedeciendo esto no solo a los deseos de quien emite el mensaje, sino que está sometido a la capacidad del receptor/a de comprender el contexto, a su interlocutor/a y sus intenciones. Esta es una similitud existente con el conjunto de la obra de Joachim Lottmann: controvertida, capaz de despertar la sonrisa y el enojo al mismo tiempo, pero indudablemente desprovista de cualquier tipo de prejuicio sobre la corrección política y con una evidente determinación a denunciar los temas más incómodos, obligando al lector/a a tenerlos presentes.

Para entender su obra y la finalidad de la misma, hemos constatado que una de las herramientas predilectas es la ironía, propia de los Popliteraten de los 90, que él ha seguido utilizando incluso cuando se valoraba el fin de la Popliteratur en el marco del fin de la Spaßgesellschaft, y que la gran mayoría de estudiosos datan el 11 de septiembre de 2001, como resultado del cambio social que provocaron los atentados a las Torres Gemelas en Nueva York. El periodista Jacob Heilbrunn resumió este sentimiento en unas pocas líneas:

Man muss nicht Nostradamus heißen, um zu prophezeien, dass der Terroranschlag vom 11. September das Ende der Spaßkultur markiert. Wer braucht noch Ironie und Hipness, Stillbewusstsein und Zynismus, wenn die Welt auf einmal wieder von ganz realen Problemen beherrscht wird? (Heilbrunn 2001)

El supuesto fin de la tendencia pop en la literatura vino acompañado por la evolución que tuvieron los autores de mayor relevancia del entorno pop alemán: Christian Kracht desarrolló la novela histórica y de viajes, Alexa Hennig von Lange se decantó por la elaboración de libros de temática familiar, aptos para todos los públicos y muy alejados de lo que había sido su estilo hasta el momento y, junto al aparente cambio de rumbo profesional que parecía tomar Benjamin von Stuckrad-Barre, la producción literaria pop parecía quedar huérfana. Sin embargo, Lottmann continúa practicando este tipo de literatura, haciendo servir la ironía como herramienta para ofrecer al lector/a la realidad desnuda, dejando que sea el receptor/a quien la analice y considere como crea correcto, utilizando estas tres formas de representación -Entpflichtung, Inversion 
y Relativierung - en su obra Endlich Kokain cuya finalidad es la crítica social, relevando la hipocresía reinante en el contexto social que presenta la obra, unido al mundo del arte y de los artistas.

Lottmann juega con la dificultad que puede suponer para el público desvelar esa primera capa que supone la paradoja, mediante situaciones grotescas, exageradas, inverosímiles o improbables, sirviéndole a su vez de excusa para plantearnos incómodas situaciones de nuestro día a día, inherentes a nosotros mismos como seres sociales y que de alguna manera intentamos ignorar para hacer más fácil nuestra vida en colectividad y como individuos. Con su denuncia, nos invita a reflexionar, pero desde un punto de partida extremo, sin guiarnos durante este proceso. Nos abandona ante un texto crudo y sincero que refleja de forma grotesca y magnificada todo aquello que, aunque se sospecha que existe, no se quiere confirmar, sin ambages ni guías, para que las deliberaciones del lector/a sean personales, propias y no condicionadas. Ningún personaje está exento de culpa ni de caricatura, todos son cómplices, frágiles ante los instintos más bajos y carentes de voluntad para evitarlos.

Lottmann es perfectamente consciente de las reacciones que tanto público como crítica pueden tener ante sus obras, pero al mismo tiempo utiliza esta situación para que sus protagonistas se puedan mostrar francos sin sutilezas, para poner de manifiesto circunstancias fuera de lo común y hacerlo sin miedo a parecer cruel o insensible. Hace servir la ironía para elaborar obras en las que cualquier problema o tema presente en la sociedad puede ser abordado sin necesidad de que aparezca todo aquello denominado como políticamente correcto. La ironía es, por lo tanto, un elemento esencial en su obra, de tal forma que no puede ser entendida sin ella. Es utilizada en su obra en general, y en Endlich Kokain en particular, como una herramienta que construye el texto, es la base sobre la que se cimientan los personajes y que explica el texto prácticamente en su totalidad, ya que es una herramienta a la que Lottmann despoja del valor eximente del que parecía haberse adueñado en la Popliteratur para conferirle la osadía de la denuncia. Aunque este hecho no la exonera de la interpretación que debe hacer de ella el receptor/a y su contextualización, lo que siempre ha sido característico de la ironía y de la literatura pop del siglo XX y que encuentra en Lottmann su vigencia en el siglo XXI. 
Podemos concluir, por lo tanto, que Lottmann no considera la ironía únicamente como una herramienta narrativa para dotar al texto de un carácter propio e inherente a la Inszenierung, sino que, en combinación con la paradoja, el estilo borderline y campy que caracteriza a su prosa, es un arma para la denuncia. Esta crítica se construye a través de lo artificial, anti-natural o extremo, careciendo de la pátina de frivolidad y superficialidad para llegar a confeccionar un discurso alrededor del objetivo, simuladamente secundario al comienzo de la novela, y que terminará dominándola sin perder el tono socarrón y paradójico del que Lottmann ha conseguido adueñarse convirtiéndolo en su sello personal.

\section{Notas}

${ }^{1}$ Tras el final de la II Guerra Mundial y su periodo de posguerra, nace en Alemania el fenómeno conocido como Spaßgesellschaft, que supone una sociedad dedicada al disfrute de la vida, a sus placeres y a la diversión pero que, a su vez, conlleva un aumento del individualismo y de pérdida de la capacidad de empatizar con los demás. La Spaßgesellschaft supone una subjetivación de las experiencias vitales, perdiéndose la conciencia de colectivo en pos de una mayor individualización de la sociedad.

${ }^{2}$ El término New Journalism hace referencia a un estilo que supone la combinación de periodismo y literatura y que se distancia del periodismo tradicional por, entre otras características, la relación que los reporteros desarrollan hacia las personas y los eventos descritos y por la forma y el estilo inspirados en los relatos cortos o en las novelas. El New Journalism narra la noticia de la actualidad desde dentro de ella mediante la conjugación de impresiones, conversaciones completas, descripciones detalladas del entorno, la ropa y todos los detalles secundarios a ojos del/de la periodista pero imprescindibles a ojos del escritor/a. En la enciclopedia británica hallamos la siguiente definición: "The New Journalists expanded the definition of journalism and of legitimate journalistic reporting and writing techniques. They also associated journalism with fiction when they described their work with phrases such as "nonfiction novel" and "narrative techniques of fiction". In so doing, they ignited a debate over how much like a novel or short story a journalistic piece could be 
before it began violating journalism's commitment to truth and facts". (https://www.britannica.com/topic/New-Journalism)

${ }^{3}$ Mitomanía: La mitomanía es un trastorno asociado al síndrome borderline y propio de las personas comúnmente descritas como mentirosas patológicas. El DRAE define la mitomanía como: "Tendencia morbosa a desfigurar, engrandeciéndola, la realidad de lo que se dice. Tendencia a mitificar o a admirar exageradamente a personas o cosas." (https://dle.rae.es/mitoman\%C3\%ADa?m=form).

${ }^{4}$ El concepto Camp, desarrollado por Susan Sontag y publicado en 1964, se refiere a aquella sensibilidad que revela el amor por el artificio y la exageración, por aquello no natural en términos estéticos pero entendido también como una cualidad inherente al comportamiento de algunas personas. Una sensibilidad que convierte en frívolo lo serio y cuyo elemento esencial es una seriedad que fracasa y que contiene la mezcla adecuada de lo exagerado, lo fantástico, lo apasionado y lo ingenuo (Sontag 1ss).

${ }^{5}$ Eiron: El diccionario Oxford define esta figura de la comedia griega como: "A stock character in ancient Greek comedy characterized by self-depreciation, modesty of speech, and awareness of irony. Hence in extended use: a character of this type. Contrasted with alazon." (https://en.oxforddictionaries.com/definition/eiron)

${ }^{6}$ El sustantivo "postureo" y el verbo "posturear", con los que se alude a la adopción de ciertos hábitos, poses y actitudes más por apariencia que por convicción, son neologismos [...]. La expresión "postureo" surge en el ámbito de las redes sociales para calificar actitudes impostadas, con un sentido que puede ir de lo irónico a lo despectivo, y se ha extendido ya en el español de España a otros ámbitos. [...] Desde el punto de vista del significado está emparentada con "postura" y sobre todo con "pose" ("postura poco natural, y, por extensión, afectación en la manera de hablar y comportarse'). (https://www.fundeu.es/recomendacion/postureo-yposturear-neologismos-validos/)

${ }^{7}$ La canción Ganz Wien, incluida en el álbum Einzelhaft de 1982, se convirtió en un éxito de masas en la década de los años 80 y en sus versos se hace referencia al consumo generalizado de drogas en la ciudad de Viena: Ganz Wien / Ist heut auf Heroin / Ganz Wien / Träumt mit Mozambin / Ganz Wien, Wien / Grieft auch zu Kokain / Überhaupt in der Ballsaison / Man sieht ganz Wien (Falco 1982).

${ }^{8}$ Puesta en escena de los Popliteraten, no solo como forma de entrar 
en el mercado literario, sino también como forma de autognosis. En los años 90 se llevaba a cabo a través de festivales literarios, presentaciones y lecturas públicas, mientras que en el siglo XXI se realiza también a través de las redes sociales: Facebook, Twitter o Instagram ayudando a los autores a establecer un contacto mucho más cercano con sus lectores y con el mercado literario.

\section{Obras citadas}

Barbey D'Aurevilly, Jules A. Über das Dandytum und über George Brummell. Ein Dandy ehe es Dandys gab. Traducido por Gernot Krämer, Matthes und Seitz, 2006.

Benéitez Andrés, Rosa. "El concepto de la ironía en la estética de Friedrich Schlegel: Contexto y recepción." Daimon. Revista Internacional de Filosofía, no 67, enero-abril 2016, pp. 39-55.

Degler, Frank y Ute Paulokat. Neue Deutsche Popliteratur. Wilhelm Fink Verlag GmbH \& Co, 2008.

Eibl, Karl. Animal Poeta. Bausteine der biologischen Kultur- und Literaturtheorie. Mentis Verlag, 2004.

Encyclopaedia Britannica. www.britannica.com/topic/New-Journalism. Consulta: 21 de mayo de 2020.

Erbe, Günter. "Der moderne Dandy. Zur Herkunft einer dekadenten Figur." Depressive Dandys. Spielformen der Dekadens in der PopModerne, editado por Alexandra Tacke y Björn Weyand, Böhlau Verlag GmbH, 2009, pp. 17-38.

Hölzel, Johann (compositor). "Ganz Wien”. Einzelhaft, A \& M, 1982. Spotify.

Goetz, Rainald. Abfall für alle: Roman eines Jahres. Suhrkamp Verlag, 1999.

Harwood, John. Critics, Values and Restoration Comedy. Southern Illinois University Press, 1982.

Heilbrunn, Jacob. "Der Ernst des Lesens. Ein Abgesang auf die deutsche Pop-literatur." SZ Magazin del 5 de octubre de 2001.

Hernández Guerrero, José A. "El humor: un procedimiento creativo y recreativo." Literatura y humor. Estudios teórico-críticos, editado por Ulpiano Lada Ferreras y Álvaro Arias Cachero-Cabal, Universidad de Oviedo, 2010, pp. 43-56.

Kreknin, Innokentij. Poetiken des Selbst. Walter de Gruyter, 2014. 
"Borderline als Autorschaft und Krankheit bei Joachim Lottmann." Autorschaftsinszenierungen als Praktiken der Subjektivierung, editado por Sabine Kyora, Transcript Verlag, 2014, pp. 327-342.

Lottmann, Joachim. Endlich Kokain. Verlag Kiepenheuer \& Witsch, 2014.

Martínez, Matías y Michael Scheffel. Einführung in die Erzähltheorie. Verlag C. H. Beck, 1999.

Matamoro, Blas. "Elogio de la ironía." Analecta Malacitana. Revista de la sección de Filología de la Facultad de Filosofía y Letras, vol. 23, $\mathrm{n}^{\mathrm{o}}$ 1, enero 2000, pp. 241-248.

Mehrfort, Sandra. Popliteratur. Zum literarischen Stellenwert eines Phänomens der 1990er Jahre. Lindemanns Bibliothek, 2009.

Oxford Dictionaries. https://en.oxforddictionaries.com/definition/eiron. Consulta: 21 de mayo de 2020.

Rauen, Christoph. Pop und Ironie. Popdiskurs und Popliteratur um 1980 und 2000. Walter de Gruyter, 2010.

Real Academia Española. Diccionario de la lengua española, $23^{\mathfrak{a}}$ ed., https://dle.rae.es/mitoman\%C3\%ADa?m=form. Consulta: 21 de mayo de 2020.

Santaemilia Ruiz, José. "Discurso irónico y personajes cómicos de la restauración inglesa: Los fops." Quaderns de Filología. Estudis literaris, Vol. VI, 2001, pp. 215-225.

Schweikle, Günther e Irmgard Schweikle, eds. Metzler Literatur Lexikon. Begriffe und Definitionen. $2^{\underline{a}}$ ed., J. B. Metzlersche Verlagsbuchhandlung, 1990.

Sendera, Alice y Martina Sendera. Borderline - Die andere Art zu fühlen. Springer Verlag, 2016.

Sontag, Susan. Notes on Camp. Dell Publishing, 1964.

Weidermann, Volker. Lichtjahre. Eine kurze Geschichte der deutschen Literaturvon 1945 bis heute. Verlag Kiepenheuer \& Witsch, 2006. Willems, Herbert. "Zur Einführung: Theatralität als Ansatz, (Ent-) Theatralisierung als These." Theatralisierung der Gesellschaft, Band 1: Soziologische Theorie und Zeitdiagnose, editado por Herbert Willems, VS Verlag für Sozialwissenschaften, 2009, pp. 13-56.

Willkommen Österreich. Eine Sendung vom 17. Januar 2008. https://www.youtube.com/watch?v=gTOeA4-W5JE\&t=2335s. Consulta: 12 de noviembre de 2018. 